\title{
Dr Vladislav Papper Joins the Editorial Board of the Journal of Fluorescence
}

\author{
C. D. Geddes
}

Published online: 21 June 2013

(C) Springer Science+Business Media New York 2013

On June $1^{\text {st }} 2013$, Dr Papper joined the editorial board of the Journal of Fluorescence. Dr Papper brings significant expertise in Organic Chemistry and Fluorescent probes.

We thank Dr Papper for agreeing to serve on the Journal's editorial Board

Dr Chris D. Geddes

Professor

Editor-in-chief: The Journal of Fluorescence

Dr. Vladislav Papper received his Ph.D. in chemistry in 2000 , from the Ben-Gurion University of the Negev in Israel. In 2003, he completed his postdoctoral studies in the group "Fast Photophysical Processes" led by Prof. Dr. Wolfgang Rettig at the Humboldt University of Berlin. In his postdoctoral studies, Vladislav had investigated the photophysical phenomenon of charge transfer in Rhodopsin using the new synthetic fluorescent analogues of retinal.

Ever since, Vladislav had worked in chemical industry managing research projects from conception to completion. In 2003-2006, he had managed a R\&D of PheroCap Ltd specializing in agrochemical formulations and new microencapsulation techniques, and had consulted Polyrizon Ltd being a CTC of the company.

Vladislav had also taught the courses in Organic Chemistry and supervised undergraduate students in the Ben-Gurion University of the Negev and in the Beer-Sheva Technological College.

In addition, Vladislav is a licensed patent attorney. In 2006-2011, he had been practicing the patent law in Israel working in different patent and law offices.

In 2011, he moved to Singapore to obtain the position of the R\&D manager in the academic CREATE program "Nanomaterials for Water and Energy Management", funded by the National Research Foundation of Singapore. He is experienced in many areas of science: organic, analytical and physical chemistry, photochemistry and photophysics, organic synthesis, biophysics, biochemistry and biotechnology. His major interests lie in the areas of organic synthesis of new fluorescent compounds, intramolecular charge transfer and use of the fluorescent molecules in biotechnological applications.
C. D. Geddes $(\bowtie)$

Baltimore, MD, USA

e-mail: geddes@umbc.edu 